www.jmscr.igmpublication.org

Impact Factor (SJIF): 6.379

Index Copernicus Value: 71.58

ISSN (e)-2347-176x ISSN (p) 2455-0450

crossref DOI: _https://dx.doi.org/10.18535/jmscr/v6i3.212

Journal Of Medical Science And Clinical Research

\title{
RHUPUS Syndrome in an 11 yr Old Child: A Rare Case Report
}

\author{
Authors \\ Sunil Ku Agarwalla', Poonam Agrawal', B. Maheshwar Rao ${ }^{3}$, Ashok Nanda ${ }^{3}$, \\ Rina Meher ${ }^{2}$
}

${ }^{1}$ Associate Professor, Department of Paediatrics, MKCG Medical college and Hospital, Berhampur, Odisha

${ }^{2}$ Senior Resident, Department of Paediatrics, MKCG Medical College and Hospital, Berhampur, Odisha ${ }^{3}$ Assistant Professor, Department of Paediatrics, MKCG Medical College and Hospital, Berhampur, Odisha

\section{Abstract}

Systemic lupus erythematosus (SLE) is a multisystem disease characterized by loss of self tolerance resulting in development of auto antibodies and formation of immune complexes. Multiple organ involvement can be seen with renal and neurological involvement carrying the worst prognosis. Overlap of JIA and JSLE is a rare clinical condition in children which has been described as an entity known as RHUPUS syndrome. Prevalence of this disorder in JSLE is 2.5\% [9]. In this paper we report a case of RHUPUS syndrome in an $11 y$ r old child with clinical features of JIA in the initial presentation and eventually turned out to be a case of SLE.

Keywords: RHUPUS syndrome, Systemic lupus erythematosus, Juvenile idiopathic arthritis.

\section{Introduction}

Systemic lupus erythematosus (SLE) is a rheumatic disease characterized by autoantibody directed against self-antigens, immune complex formation, and immune deregulation, resulting in damage to essentially any organ. Childhood SLE is rare before 5 years of age and it generally presents in adolescence (11-12yrs), with girls outnumbering boys $2-5: 1^{[1]}$. In $10-20 \%$ of SLE patients the diagnosisis made for the first time in childhood $^{[2-6]}$. The disease can affect any organ but the most frequent are the joints $(95 \%)$, skin $(80 \%)$, blood vessels and cells $(85 \%)$, kidney (30$50 \%)$, heart and nervous system (60\%). Because symptoms \& findings may develop serially over several years and may not be present at one time, diagnosis may require long term follow-up.
RHUPUS syndrome is an unusual presentation of lupus in children. On literature review, $45 \%$ cases had joint erosion \& $70 \%$ cases had polyarticular involvement. It seems that clinical features and outcome of RHUPUS syndrome are different in children \& adults due to difference between RA \& JIA. We suggest the term Juvenile RHUPUS for overlap of JIA and JSLE. For the first time RHUPUS syndrome was described by Schur in 1971 but the first clinical observation of this syndrome has been described in 1960 by Toone ${ }^{[9]}$.

\section{Case Report}

An 11yr old male child was brought with complaints of vomiting for 2 days. Examination revealed severe pallor, icterus, $\mathrm{B} / \mathrm{L}$ pitting pedal edema, swelling of bilateral ankle joints, hepatosplenomegaly and ascites. 
Past H/o fever with swelling of left knee joint 3yrs back for which patient had taken ATT for 6 months, symptoms subsided only to reappear after some months when the patient was diagnosed with JIA (Juvenile idiopathic arthritis) and since then was on tab methotrexate and NSAIDs.

Investigations showed microcytic hypochromic anaemia with $\mathrm{Hb}-3.8$ gm\%, TLC- 19,500/cmm, TPC- 25,000/cmm, retic.count-16\%, ESR$90 \mathrm{~mm} / 1^{\text {st }} \mathrm{hr}$, raised BUN(s.urea- $170 \mathrm{mg} / \mathrm{dl}$, s.creatinine-5.3mg/dl), DCT-negative, urine examination revealing plenty of RBCs \& albumin ++; USG abdomen- normal except mild ascites; ANA-strongly positive, ds DNA- negative ;liver function test being within normal limits except bilirubin (total-3.8, direct-1)

Patient fulfilled 5 of the 11 criteria of the 1997 ACR (American College of Rheumatology) revised criteria for diagnosis of SLE (arthritis, serositis, nephropathy, haemolytic anaemia, thrombocytopenia and positive ANA without any skin or mucosal involvement). Patient was managed with IV fluids, 1 unit of PRBC and steroid was started soon after diagnosis. Two days after steroid our patient developed acute gastritis. Thus, steroid was stopped \& IV methyl prednisolone given for 5days. After that patient was discharged with low dose steroid \& hydroxyl chloroquine for follow up.

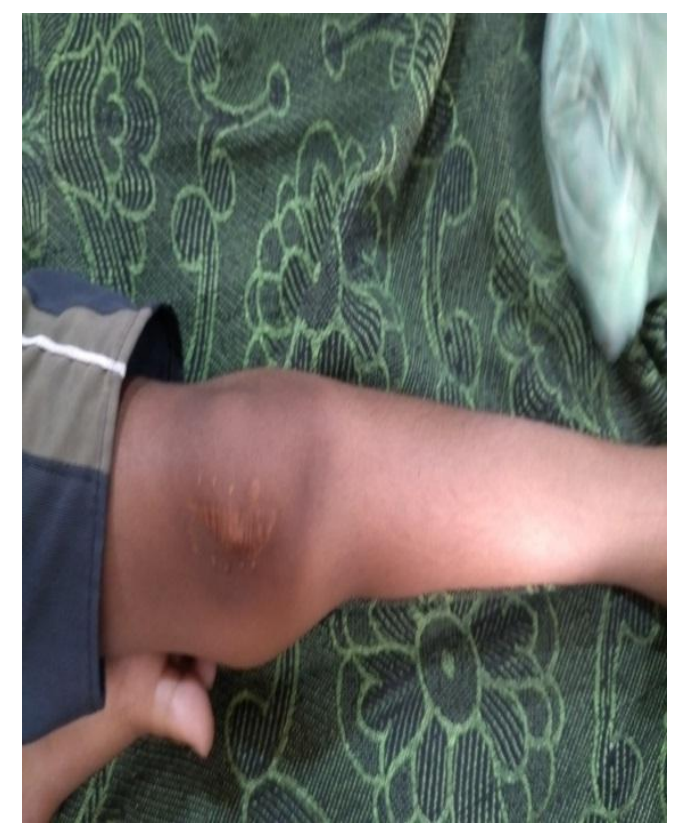

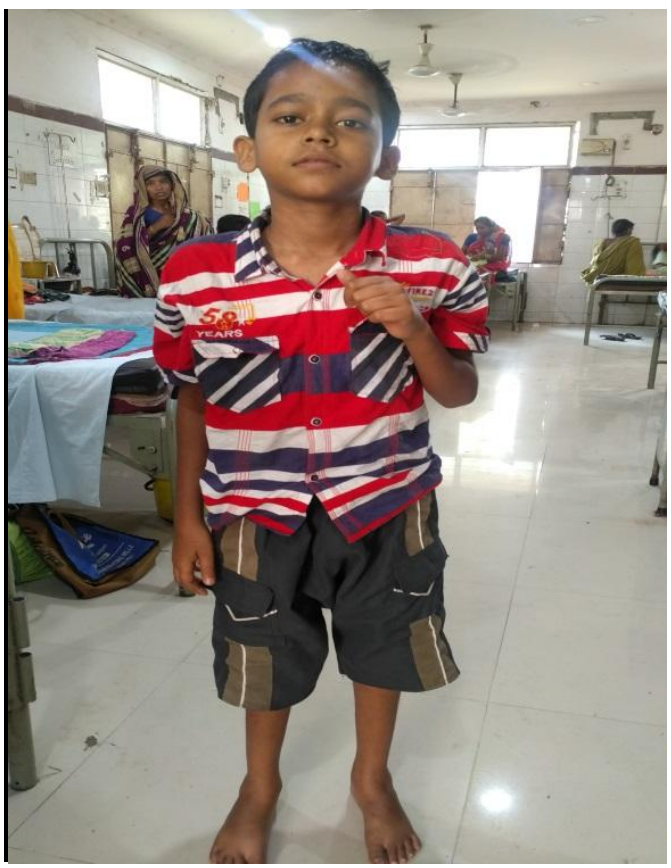

\section{Discussion}

Systemic lupus erythematosus (SLE) is one of the chronic autoimmune diseases affecting the internal organs such as skin, joints, kidneys, nervous system, heart, blood vessels, blood cells and lungs by deposition of immune complex ${ }^{(1,2)}$. In $10-20 \%$ of SLE patients the diagnosis is made for the first time in childhood. Children have more severe disease in comparison with adults. The patients may present with many years of symptoms or with acute history of life-threatening disease $^{[7-8]}$. Common initial and chronic complaints include fever, malaise, fatigue, joint pain, temporary loss of cognitive abilities, many present with pyrexia of unknown origin (PUO). Because they are so often seen with other diseases, these signs and symptoms are not part of the diagnostic criteria for SLE. Skin manifestations like rash, photosensitivity, pigmentation, DLE, bullous lesions and mucositis are present in $80 \%$ cases.

Patient with SLE may present with fever, weakness, fatigue, weight loss as the initial symptoms. According to Biesecker et al, joint involvement is the most common manifestation of $\mathrm{SLE}^{[8]}$. Arthritis, usually symmetric, most commonly affects proximal interphalangeal joints, knees, wrists, and metacarpophalangeal joints. 
Our case was having an interesting presentation left knee arthritis $3 y$ rs back for which arthrotomy was done and ATT was given for 6 months. Towards the end of ATT (Category1 as per RNTCP) regimen the child developed other large joint involvement clinching the diagnosis of JIA, for which the patient was put on methotrexate \& etoricoxib for $2 y r$ by the local treating physician. Till the end of $3^{\text {rd }} \mathrm{yr}$ of illness multisystem involvement was not seen.

When child came to us with vomiting for 2 days, a diagnosis of drug induced gastritis was made. Getting severe pallor, icterus, hepatosplenomegaly along with polyarthritis we suspected sickle cell disease but abnormal renal function test, normal $\mathrm{Hb}$ pattern on HPLC, haemolytic anaemia, thrombocytopenia, polyarthritis...all gave a clue towards collagen vascular disease like SLE. After getting ANA profile, final diagnosis of SLE was made but the typical skin \& mucosa involvement was not seen in our case. This made our case difficult to think towards SLE even after multiple visits to multiple physicians in 3 yrs. There is evidence that paediatric lupus may develop in patients previously diagnosed with polyarticular or systemic juvenile idiopathic arthritis.

On real ground our case presented as JIA which in the long run of $3 \mathrm{yrs}$ turned out to be a case of JSLE. Thus the final entity 'RHUPUS syndrome' is the appropriate diagnosis in our case which is a rare entity as very few cases have been described in literature. Further studies are needed for this entity. We recommend all patients with JIA and positive ANA to have follow-up for a long time (at least 4yrs) for juvenile RHUPUS syndrome and to be evaluated for JSLE if they develop cutaneous or haematological symptoms ${ }^{[9]}$.

\section{References}

1. James, William Berger, Imothy, Elston, Dirk (2005) Andrews Diseases of the Skin: Clinical Dermatology. (10edn), Saunders, Philadelphia, USA, p. 1-51.
2. Nepom BS, Schaller JG (1984) Childhood systemic lupus erythematosus. Prog Clin Rheumatol 1: 33-69.

3. Tucker LB, Menon S, Isenberg DA (1995) Systemic lupus in children:daughter of the Hydra? Lupus 4(2): 83-85.

4. Schaller J (1982) Lupus in childhood. Clin Rheum Dis 8(1): 219-228.

5. Ting CK, Hsieh KH (1992) A long term immunological study of childhood onset systemic lupus erythematosus. Ann Rheum Dis 51(1): 45-51.

6. Rosenberg AM (1994) Systemic lupus erythematosus in children. Springer SeminImmunopathol 16(2-3): 261-279

7. Tucker L, Menon S, Schaller J, Isenberg D. Adult-and childhood-onset systemic lupus erythematosus: a comparison of onset, clinical features, serology, and outcome. Rheumatology. 1995;34(9):86672.

8. Biesecker G, Lavin L, Zaskind M, Koffler D. Cutaneous localization of the membrane attack complex in discoid and systemic lupus erythematosus. N Engl J Med 1982 Feb 4;306(5): 264-270.

9. Vahid Ziaee, Mohammad Hassan Moradinejad, and Reyhaneh Bayat, "RHUPUS Syndrome in Children: A Case Series and Literature Review," Case Reports in Rheumatology, vol. 2013, Article ID 819629, 4 pages, 2013.

10. E. G. Cavalcante, N. E. Aikawa, R. G. Lozano, A. P. Lotito, A. A. Jesus, and C. A. Silva, "Chronic polyarthritis as the first manifestation of juvenile systemic lupus erythematosus patients," Lupus, vol. 20, no. 9, pp. 960-964, 2011.

11. R. S. Panush, L. Edwards, S. Longley, and E. Webster, "RHUPUS syndrome," Archives of Internal Medicine, vol. 148, no. 7, pp. 1633-1636, 1988.

12. B. Sharma, "RHUPUS: report of 3 cases," Journal of Indian Rheumatology Association, vol. 11, pp. 51-54, 2003. 
13. A. Fernández, G. Quintana, F. Rondón et al., "Lupus arthropathy: a case series of patients with rhupus," Clinical Rheumatology, vol. 25, no. 2, pp. 164167, 2006. 